\title{
Transformaciones del Derecho internacional por los objetivos de desarrollo sostenible*
}

\author{
Sustainable Development Goals and changes of International law
}

Carlos R. FERNÁNDEZ LIESA

Catedrático de Derecho Internacional Público

Universidad Carlos III de Madrid

carlos@inst.uczm.es

Resumen: Esta contribución es una aproximación a la noción de desarrollo en el Derecho internacional. La cambiante naturaleza del desarrollo debido a la sostenibilidad afecta a los rasgos del Derecho internacional. La concepción del Derecho internacional se ve afectada por la teoría de las normas y de los sujetos.

Palabras claves: Desarrollo sostenible. Derecho internacional. Derechos humanos.
Abstract: This contribution is an approximation to the concept of development in International law. The changing nature of development, due to sustainability, affects the International law features. International law conception is affected in theory of norms and subjects.

Keywords: Soustainable development. International law. Human rights.

Sumario: I. EL NUEVO MARCO DE LOS OBJETIVOS DE DESARROLLO SOSTENIBLE. a) Aproximación a la noción de desarrollo sostenible. b) Un desafío integral para la Comunidad internacional. c) Una transformación en la concepción del desarrollo: La naturaleza del desarrollo sostenible. d) La gobernanza del desarrollo sostenible en la globalización. II. TRANSFORMACIONES PARA EL DERECHO INTERNACIONAL. a) Transformaciones en los objetivos b) Transformaciones del marco normativo internacional c) Las transformaciones en los actores y sujetos del Derecho internacional. III. REFLEXIONES FINALES.

\section{El NUEVO MARCO DE los OBJETIVOS DE DESARROLlO SOSTENIBLE}

\section{a) Aproximación a la noción de desarrollo sostenible}

$\mathrm{n}$ el Informe Nuestro futuro común ${ }^{1}$ se indica que el desarrollo sostenible es el desarrollo que satisface las necesidades de la generación presente sin comprometer la capacidad de las generaciones futuras para satisfa-

* Este trabajo constituye un resultado del proyecto de investigación DER 2014-55484-P, titulado Actores económicos internacionales y derechos humanos. Especial relevancia para España.

1 Informe de la Comisión Mundial sobre el Medio ambiente y el desarrollo «Nuestro futuro Común» (A/42/427 anexo), llamado Informe Bruntland. 
cer sus propias necesidades. Este enfoque intergeneracional se ha visto complementado por otros enfoques, como el medioambiental, desde la Cumbre de Río de Janeiro de 1992. Luego evolucionaría también hacia el enfoque de inclusión social, sobre todo desde la Cumbre de Johannesburgo de Desarrollo sostenible, de 2002. En 2012, en la Declaración final de la Cumbre Río+20 se plantea esta visión tripartita del desarrollo sostenible cuando se indica:

«Es necesario lograr el desarrollo sostenible promoviendo un crecimiento sostenido, inclusivo y equitativo, creando mayores oportunidades para todos, reduciendo las desigualdades, mejorando los niveles de vida básicos, fomentando el desarrollo social equitativo y la inclusión, y promoviendo la ordenación integrada y sostenible de los recursos naturales y los ecosistemas, que contribuye, entre otras cosas, al desarrollo económico, social y humano y facilita al mismo tiempo la conservación, la regeneración, el restablecimiento y la resiliencia de los ecosistemas frente a los problemas nuevos y en ciernes» ${ }^{2}$.

Este triple desafío económico, social y medioambiental constituye el ítem central de la actual Agenda internacional de la cooperación. Ya lo era con los Objetivos del milenio, y estaba presente en proyectos como el Global compact, en Naciones Unidas, en los debates sobre la Responsabilidad social corporativa, en el papel de las multinacionales en la globalización o los principios Rectores sobre Empresas y derechos humanos. Se había tomado conciencia del reto y, progresivamente, el desafío ha ido madurando y avanzando, hasta el punto actual en el que todavía queda mucho por hacer ${ }^{3}$.

El término desarrollo sostenible surge por la preocupación por la excesiva explotación de los recursos del planeta, y la publicación del informe Los limites del crecimiento ${ }^{4}$, que suponía un posible freno al crecimiento económico y cuyos críticos indicaron que no se tenían en cuenta los avances tecnológicos. Como indica Pérez de Armiño la conciencia de los límites del crecimiento supuso un paso adelante que cambiaría la concepción del desarrollo, si bien no se asumen los profundos cambios necesarios en los modelos económicos y

2 Documento final Río+20, Asamblea General de las Naciones Unidas 2012, párr. 4.

3 SChamnd, J. y WARD, C. H., Sustainable development. The challenge of transition, VV.AA., Cambridge University Press, 2000, 220 pp.

4 Vid. sobre el origen y evolución del término PÉREZ DE ARMIÑo, K., Diccionario de acción humanitaria y cooperación al desarrollo, Icaria editorial, 2006, pp. 180-182. 
sociales. Con la aprobación por la Asamblea General de Naciones Unidas de los Objetivos de desarrollo sostenible en 2015 pasa a plasmarse como una hoja de ruta general para la Comunidad internacional.

Esta hoja de ruta tiene, sin embargo, muchas páginas en blanco, que habrá que ir rellenando a través del desarrollo progresivo del Derecho internacional y del impulso a políticas nacionales e internacionales que la doten de contenido. De otro lado es una hoja de ruta que no se ha diseñado, como veremos más adelante, desde los esquemas habituales del Derecho internacional, lo que conlleva ciertas debilidades.

El desarrollo sostenible esta de moda, lo que ha conducido, como ha señalado acertadamente Rodrigo, a un uso inflacionario de la expresión, que corre el riesgo de llevar la expresión a su distorsión, cuando no a su irrelevancia 5 .

Se puede esperar que, de tener éxito, grandes desarrollos del Derecho internacional se cobijen bajo esta expresión. No hay que desechar, aunque esperemos que ese horizonte no se produzca que el Derecho internacional retroceda en el sentido de no ir hacia la satisfacción de los intereses generales de la humanidad. Pero sería deseable que vaya avanzado, como de hecho lo hace con avances y retrocesos en la idea de servir de marco jurídico general de la protección del interés público de la Comunidad internacional ${ }^{6}$. A día de hoy el desafío del desarrollo sostenible tiene un conjunto de caracteres. Se trata de un reto general, integral y universal. El que sea un reto general implica que sus objetivos son múltiples, como es evidente por el número de diecisiete, y que tienen que ver con multitud de aspectos, como son la pobreza, el hambre, la enfermedad o las privaciones, la ausencia de violencia, el acceso a la educación, el bienestar físico, mental y social, el acceso a agua potable y saneamiento, la mejor higiene y alimentos, la existencia de hábitats humanos seguros, de energía asequible, fiable y sostenible ${ }^{7}$.

Todos estos objetivos tienen relación con el goce efectivo de los derechos humanos. Se trata de que no sean solo una retórica, sino que sean reales y eficaces, lo cual

5 Rodrigo, A. J., El desafío del desarrollo sostenible, Tribuna Internacional 17, 2015, p. 18.

6 Sobre las diferentes tesis y desarrollos, así como incertidumbres que en el Derecho internacional público plantea la defensa del interés público, cabe destacar una síntesis de las tendencias (constitucionalismo, derecho administrativo global, pluralismo postnacional, otros enfoques) en el trabajo de CaSANOVAS, O., «La dimensión pública del Derecho internacional actual», en BouZA, N.; García, C. y RodrigO, A. (dirs.), La gobernanza del interés público global. xXV fornadas de la AEPDIRI, Tecnos, 2015, pp. 57-81.

7 Vid. en este sentido Transformar nuestro mundo: la Agenda 2030 para el desarrollo sostenible. Resolución aprobada por la Asamblea General el 25 de septiembre de 2015. 
en el mundo contemporáneo no solo depende del desarrollo de las normas internacionales y nacionales de derechos humanos. Es un nuevo enfoque para el Derecho internacional de los derechos humanos. Una aproximación que no se basa tanto en el binomio Derecho humano/obligación del Estado cuanto en impulsar políticas nacionales e internacionales que favorezcan un contexto de realización de los derechos humanos. No se basan tanto en la técnica jurídica clásica cuanto en promocionar en una determinada dirección la acción de los gobiernos y de la Comunidad internacional. Constituye, a mi juicio, un complemento más que una alternativa. Esperemos que esto no diluya lo conquistado desde la perspectiva del Derecho. Es decir, un Estado que avance en los indicadores pero que no cumpla las obligaciones internacionales que tiene en derechos humanos puede utilizar esta situación.

De otro lado los ODS constituyen un reto universal, pues requieren una cooperación intensa de toda la Comunidad internacional (la denominada Alianza mundial para el desarrollo sostenible) así como la adopción de medidas por todos los sujetos y actores, incluidas muy especialmente las empresas.

Es un reto nuevo, más ambicioso, reciente y revolucionario. Es nuevo en la medida en que solo se ha tomado conciencia hace muy poco, en particular desde la Declaración El futuro que queremos, de la AGONU, 2012, de la necesidad de «imprimir un impulso renovado a nuestra colaboración en la búsqueda del desarrollo sostenible». También supone una novedad que se pasa de una aproximación norte sur a otra que afecta a todos los países, pues todos están obligados por los ODS, a diferencia de lo que ocurría con los ODM (Objetivos de desarrollo del Milenio, que tenía la lógica países desarrollados-países en desarrollo. Es más ambicioso y de mayor calado para las relaciones internacionales, pues supone, como indica Gabriel Ferrero, del equipo de planificación del desarrollo post-2015, un cambio de paradigma que afecta a la concepción y articulación del desarrollo ${ }^{8}$.

Las medidas que se deben adoptar para alcanzar los ODS suponen también una transformación cualitativa del funcionamiento de la sociedad internacional. Es un reto cuya consecución supone que el desarrollo sea compatible con el medio ambiente y los derechos humanos. Se trata de un reto integral e indivisible, que requiere de políticas que estén concebidas en su conjunto con

8 Ferrero, G., «Una agenda de desarrollo universal después de 2015. Implicaciones para las políticas de desarrollo», Objetivos de desarrollo sostenible: una mirada a 2015, Tiempo de Paz, $\mathrm{n}^{\circ} 115$ (invierno de 2014), pp. 5-17. 
esta perspectiva coordinada. La Agenda 2030 para el desarrollo sostenible, que pone el acento en las personas, el planeta y la prosperidad ${ }^{9}$, tiene por objetivo la construcción de sociedades pacíficas, justas e inclusivas, que protejan los derechos bumanos y creen las condiciones para un crecimiento económico, sostenible, inclusivo y sostenido. Se trata de un gran viaje a favor de la dignidad bumana, en el que nadie debiera quedarse atrás, como ha señalado la AGONU.

\section{b) Un desafío integral para la Comunidad internacional}

El desafío es de todos, y sobre los diecisiete objetivos de desarrollo sostenible ${ }^{10}$. Por ejemplo, el objetivo número trece indica que se deben adoptar medidas urgentes para combatir el cambio climático y sus efectos, y se indican muchas. Cada objetivo tiene su hoja de ruta, con más de 169 medidas, y con grandes desafíos pero mayores dificultades, lo que hace que estemos ante un desafío complejo y de gran calado para toda la Comunidad internacional.

Cada objetivo es un mundo en sí mismo. Por ejemplo, en relación con el cambio climático, la panoplia de desafíos, medidas, y obstáculos es enorme. En junio de 2016 Francia fue el primer país industrializado en ratificar el acuerdo de París, para cuya entrada en vigor tendrán que hacerlo un mínimo de 55 Estados que representen al menos un 55\% de las emisiones globales de efecto invernadero. Este acuerdo había sido el principal resultado de la conferencia de París sobre cambio climático, celebrada entre 195 países y que adoptó un texto el 12 de diciembre de 2015. Las dificultades para el acuerdo derivan de los intereses de países que, como China, Estados Unidos, la Unión Europea, India, Rusia o Japón son los principales emisores.

9 Transformar nuestro mundo: la Agenda 2030 para el desarrollo sostenible. Res aprobada por la Asamblea General de Naciones Unidas el 25 de septiembre de 2015

10 Los objetivos son los siguientes: 1. Poner fin a la pobreza en todas sus formas y en todo el mundo. 2. Poner fin al hambre, lograr la seguridad alimentaria. 3. Vida sana. 4. Educación inclusiva y equitativa. 5. Igualdad de género. 6. Agua y saneamiento. 7. Energía asequible. 8. Crecimiento sostenido, inclusivo y sostenible. 9. Infraestructuras resilientes, industrialización inclusiva y sostenible. 10. Reducir la desigualdad en los países. 11. Ciudades inclusivas y asentamientos humanos. 12. Consumo y producción sostenible. 13. Cambio climático. 14. Utilización sostenible de los océanos, los mares y los recursos marinos. 15. Uso sostenible de ecosistemas terrestres, gestión sostenible de los bosques, lucha contra la desertificación, detención de la degradación de las tierras y detener la pérdida de la biodiversidad. 16. Promoción de sociedades pacíficas e inclusivas para el desarrollo sostenible. 17. Fortalecer los medios de implementación y revitalizar la Alianza Mundial para el desarrollo sostenible. 
Frenar el cambio climático es un desafío de enorme complejidad por muchas razones ${ }^{11}$. Es muy difícil movilizar a la Comunidad internacional, pues los Estados tienen intereses y posiciones diferentes (los hay exportadores e importadores de combustibles fósiles; los hay ricos y pobres; grandes y pequeños consumidores de energía; más y menos vulnerables; democráticos o no, etc.). Además la crisis climática afecta más a las generaciones venideras que a las actuales, lo que no moviliza a la clase política. Se trata de un desafío a largo plazo, que exige medidas muy complejas y coordinadas y puede tener enfrente a poderosos enemigos con grandes intereses. Cada uno de los objetivos es un desafío enmarcable dentro de la lógica de la denominada sociedad del riesgo mundial. Los riesgos globales, sean ecológicos, financieros, terroristas, deben gestionarse para evitar que se conviertan en catástrofes, en la denominada sociedad del riesgo mundial ${ }^{12}$.

Pero en esta sociedad del riesgo mundial no hay recetas claras en todos los casos. Más bien, tanto a nivel interno como internacional, hay que gestionar la adopción de decisiones con cierta incertidumbre. $Y$ es que como indica Innerarity ${ }^{13}$ a pesar de que las ciencias han ampliado mucho la cantidad de saber seguro, cuando se trata de sistemas de elevada complejidad (como el clima), es difícil obtener explicaciones causales o previsiones exactas, y se produce en ese caso el «no-saber». De ahí que si juntamos la incertidumbre con la tendencia de los Estados a defender sus exclusivos intereses, no cabe duda de que encajar la realización de los 17 objetivos en una Comunidad internacional de Estados con sus características es una tarea difícilmente realizable.

De ahí que la era del desarrollo sostenible sea más un proyecto, que una realidad. Es, un proyecto que, señala Sachs, pretende la interacción entre sistemas complejos, como son la economía, la sociedad global y el medio ambiente. De ahí la necesidad de un enfoque holístico, en el sentido de que la sociedad internacional debe perseguir simultáneamente objetivos económicos, sociales y ambientales, y una buena gobernanza ${ }^{14}$. El Derecho internacional está difícilmente preparado para estos enfoques holísticos desde la lógica tra-

11 SaCHS, J., The Age of sustainable development, Columbia University Press, Nueva York, 2014. [Traducido al español, La era del desarrollo sostenible, prólogo de Ban Ki-Moon, Secretario General de las Naciones Unidas, Paidós Empresa, 2016, 602 pp.].

12 BECK, U., La sociedad del riesgo mundial, Paidós, 2008.

13 Innerarity, D., La democracia del conocimiento. Por una sociedad inteligente, Paidós, 2011, 256 pp., p. 64.

14 Vid. SACHS, J., La era del desarrollo sostenible, Prólogo de Ban Ki-Moon, Paidós, 2014, pp. 19-21. 
dicional derecho-obligación. Además, la gobernanza de la Comunidad internacional además ya no puede limitarse a los gobiernos sino también a otros actores como las empresas multinacionales, que también deben respetar las leyes, el medio ambiente y objetivos como la erradicación de la extrema pobreza ${ }^{15}$.

\section{c) Una transformación en la concepción del desarrollo: la naturaleza del desarrollo sostenible}

La expresión desarrollo sostenible permite preguntarse sobre su naturaleza. El art.1.1. de la Res. AGONU 41/128 (1986) (Declaración sobre Derecho al desarrollo) considera el derecho al desarrollo un derecho humano inalienable, algo discutible en términos de derechos de titularidad individual ${ }^{16}$. En virtud de ese derecho «todos los seres humanos y todos los pueblos están facultados para participar en su desarrollo económico, social, cultural y político en el que puedan realizarse plenamente todos los derechos humanos y libertades fundamentales, a contribuir a su desarrollo y a disfrutar de él». En el mismo sentido se pronuncian otros instrumentos internacionales ${ }^{17}$.

La Declaración de 1986 sentó las bases para la consideración de un concepto de derecho al desarrollo como derecho humano multidimensional de realización progresiva. Diversos instrumentos y declaraciones internacionales han indicado que el derecho al desarrollo constituye un derecho humano. Para Cançado Trindade ${ }^{18}$ había «cristalizado definitivamente en el Derecho internacional de los derechos humanos que, de esa manera, se va ampliando y enriqueciendo, constituyendo el nuevo ethos de nuestro tiempo». Gross Espiell fue uno de los primeros en considerar el derecho al desarrollo como un dere-

15 Vid. el interesante libro colectivo Oliver Williams (ed.), Sustainable development. The UN Millennium development goals, The UN global compact, and the common good, VV.AA., University of Notre Dame Press, Indiana, 2014, 415 pp.

16 Vid. sobre esto mi libro El Derecho internacional de los derechos humanos en perspectiva histórica, Thomson Reuters, 2013.

17 Vid. Bermejo García, R. y Dougan Beoca, J., «El derecho al desarrollo: Un derecho complejo con contenido variable», Anuario de Derecho internacional (1986), pp. 211-249; OlIVA MARTINEZ, D., El derecho al desarrollo y la cooperación internacional, Cideal, 2012; MANERO SALVADOR, A., «Cuestiones jurídicas sobre el derecho al desarrollo como derecho humano», Derechos y libertades, $\mathrm{n}^{\circ} 15$ (2006), pp. 257-279.

18 Cançado Trindade, A.A., Tratado de directo internazionale dos direittos bumanos, vol. II, Safe, Porto Alegre, Brasil, 1999, p. 329. 
cho individual, consecuencia del reconocimiento de los derechos económicos, sociales y culturales y del derecho a la vida ${ }^{19}$.

En la misma línea indica Flory ${ }^{20}$ que el derecho al desarrollo es a un pueblo lo que los derechos humanos son al individuo, por lo que representaban la transposición de derechos humanos al nivel de la Comunidad internacional, con el contenido de los derechos sociales. Visto desde este prisma el derecho al desarrollo constituye un derecho sintesis de un conjunto de derechos bumanos, como indicaba García-Amador ${ }^{21}$.

Algunos autores estimaron que el derecho al desarrollo no era la mera suma o yuxtaposición de derechos sino un derecho distinto que implica un replanteamiento de la estrategia internacional de derechos humanos, cuya autonomía conceptual residiría en su carácter de derecho a los medios ${ }^{22}$. En esta línea el relator Sengupta definió el derecho al desarrollo como un derecho a un proceso -particular- de desarrollo, en el que pueden realizarse plenamente todos los derechos humanos y libertades fundamentales ${ }^{23}$. Esta aproximación no aporta mucho nuevo en relación con los criterios de indivisibilidad, interdependencia y naturaleza jurídica de todos los derechos humanos. El considerar el derecho

19 Gross Espiell, H., Derecho internacional del desarrollo, Cuadernos de la Cátedra J.B. Scott, Universidad de Valladolid, 1975, 56 pp.; ID., «El derecho al desarrollo veinte años después: Balance y perspectivas», en Reflexiones tras un año de crisis, Universidad de Valladolid, 1996, p. 38; PÉREZ GONZÁLEZ, M., «Algunas reflexiones sobre el derecho al desarrollo en su candidatura a derecho humano», El Derecho internacional en un mundo en transformación. Liber Amicorum en homenaje al Prof. E. Fiménez de Aréchaga, Montevideo, 1995, pp. 321 ss.

20 FLORY, M., «Inégalité économique et évolution du Droit International», Pays en voie de développement et transformation du Droit International, Colloque d'Aix en Provence, SFDI, 1974, pp. 1140, p. 34.

21 García-Amador, F. V., El Derecho internacional del desarrollo. Una nueva dimensión del Derecho internacional económico, Civitas, 1987; CANÇADO TRINDADE, A., «The contribution of recent World conferences of the United Nations to the relations betweenn sustainable development and economic, social and cultural Rights», Les hommes et l'environment. En bommage à Alexander Kiss, Edition Frinon-Roche, París, 1998, pp. 119-146.

22 Abellan Honrubia, V., «Algunas consideraciones sobre el nuevo orden económico internacional», ONU: Año XL, Revista de la Facultad de Derecho de la Universidad Complutense, 13, monográfico (abril de 1987), pp. 213-221; PÉREZ GonZÁlEZ, M., «El derecho al desarrollo como derecho humano», El derecho al desarrollo o el desarrollo de los derechos, Universidad Complutense, p. 96; M'BAYE, K., «Le droit au développement comme un droit de l'homme», Révue des droits de l'homme (1972), pp. 503 ss.; VV.AA., Fernández Liesa, C., MARiÑo MENÉNDEZ, F., El desarrollo y la cooperación internacional, Universidad Carlos III de Madrid-BOE, Madrid, 1997.

23 Sengupta, A., Tercer Informe del experto independiente sobre el Derecho al desarrollo, presentado de conformidad con la Res. 2000/5, de la Comisión de derechos humanos (grupo de trabajo sobre Derecho al desarrollo), E/ CN.4/2001/WG.18/2, de 2 de enero de 2001. 
al desarrollo no la suma de un conjunto de derechos sino también un derecho al proceso no aporta nada nuevo porque la realización de los derechos siempre es progresiva.

El que se pueda hablar con buen criterio de desarrollo humano no significa que nos encontremos ante un derecho humano individual en sentido estricto. La construcción del desarrollo como derecho humano individual tiene un sentido finalista y simbólico, por su dimensión ética ${ }^{24}$. Pero no constituye en sentido estricto un derecho humano individual ${ }^{25}$.

En la misma línea la noción de desarrollo sostenible aparece vinculada más a la idea de proceso de la Comunidad internacional, que de derecho bumanos. Incluso supera el binomio derecho-obligación tradicional. El desarrollo sostenible se podría definir como un concepto puente -como ha indicado el Secretario General de Naciones Unidas- cuyo objetivo es unir no solo los tres aspectos -desarrollo económico, desarrollo social y protección del medio ambiente- sino también a los países desarrollados y en desarrollo, los gobiernos, las empresas, la sociedad civil, los conocimientos científicos y las políticas públicas, las generaciones presentes y venideras. Estos nuevos conceptos del desarrollo no se miden en términos clásicos de obligaciones internacionales, sino de rentas per capita, PIB, indicadores sociales, de desarrollo humano, nutrición, servicios de energía, tasa de pérdida de especies y biodiversidad y otros muchos. El objeto fundamental del desarrollo sostenible es que estos tres pilares sean una meta única y se vaya avanzando en el cumplimiento de los compromisos que lo permitan. Además, el desarrollo sostenible tiene que ver con tres transiciones relacionadas entre sí. La demográfica y la estabilización de la población mundial; la del desarrollo y el reparto de los beneficios de manera equitativa entre todos los segmentos de la sociedad mundial; y el asegurar que el uso de materiales y la generación de desechos estén dentro de la capacidad de regeneración y absorción planetario.

24 FLORY, M., «A propos des doutes sur le droit au développement», Les hommes et l'environment. En hommage à Alexander Kiss, 1998, pp. 165 ss.; VASAK, K., «Le droit International des droits de l'homme», RCADI (1974-IV); URIBE VARGAS, «La troisième génération des droits de l'homme», RCADI (1984), t. 359; M'BAYE, «Le droit au développement comme un droit de l'homme», Révue des droits de l'homme (1972), 505 pp; Alston, P. y Robinson, M., Human Rights and development. Towards mutual reinforcement, Oxford University Press, 2005.

25 Abellan Honrubia, V., «Sobre el método y los conceptos en Derecho internacional público», Soberania del Estado y DI. Homenaje al Prof. F.A. Carrillo Salcedo, Sevilla, 2005, pp. 55-74, p. 73 
Desde la perspectiva de los derechos humanos hay autores como Juste Ruiz $^{26}$ que consideran que se ha formulado el derecho bumano al desarrollo sostenible. Esto puede defenderse, pero tal vez no sea el ángulo para relevante para su efectividad. En todo caso, ese derecho humano se habría reconocido progresivamente desde la declaración de Estocolmo sobre el medio humano, de 1972, que ya retenía algunos elementos esenciales del desarrollo sostenible, así como en otros instrumentos internacionales posteriores como la Carta de derechos y deberes económicos de los Estados de 1974 (art 30) o la Carta mundial de la naturaleza; pero será fundamentalmente la Declaración de Río sobre el medio ambiente y el desarrollo (1992), y otras más recientes.

Tampoco hay que desechar que lo que hoy en día no es un derecho mañana lo sea. En el momento de escribir estas líneas por ejemplo se ha firmado el acuerdo de paz entre las FARC y el gobierno colombiano que se basa, desde la perspectiva del derecho constitucional colombiano, en diversas disposiciones que se refieren al derecho a la paz. Se trata por tanto de una innovación constitucional que se engancha en un derecho a la paz del que, hasta ese momento, no era previsible que tuviese consecuencias en el plano del derecho. Ahora bien, en corrección de pruebas dicho acuerdo ha sido desechado en plebiscito el 2 de octubre, por el pueblo colombiano, lo que no significa que el derecho a la paz no exista, sino que deberá buscar nuevas vías de realización, en su caso.

Lo mismo puede suceder con el derecho al desarrollo sostenible que si bien parece hoy una quimera, puede en un futuro, como anuncian algunos autores, ser la percha de importantes desarrollos e interpretaciones del Derecho internacional. No está de más pensar que dada la naturaleza multidimensional del desarrollo sostenible y sus rasgos nos encontramos ante una noción que tiene relación, fundamentalmente, con el valor de la solidaridad en la Comunidad

26 Juste Ruiz, J., «El desarrollo sostenible y los derechos humanos», Soberanía del Estado y derecho internacional. Homenaje al Profesor Fuan Antonio Carrillo Salcedo, Universidades de Córdoba, Sevilla y Málaga, Sevilla, 2005, pp. 757-778. Asimismo en cuanto a la relación desarrollo y medio ambiente: MARTIN ARRIBAS, J. J., «El envite del Derecho internacional a favor de una simbiosis entre el desarrollo y el medio ambiente», El desarrollo y la cooperación internacional, Edición a cargo de Fernando M. Mariño Menéndez y Carlos R. Fernández Liesa, UCIIIM-BOE, Madrid, 1997, pp. 233-273; PRIEUR, M., «Démocratie et droit de l'environment et du développement», RJE (1993/1), pp. 23-30; GOMEZ IsA, F., «Desarrollo sostenible: hacia una vinculación más estrecha entre la economía y la ecología», Transformaciones estructurales en el actual escenario económico y sus proyecciones de futuro. Homenaje a D. Fosé María Solozabal, Universidad de Deusto, 1996. PIETTE, J., «Evolution institutionnelle et modes d'intervention du Droit international de l'environment et du dévelopment», RfE (1993), 1, pp. 5 ss. 
internacional. La idea de los valores en la Comunidad internacional y en el DI tiene escaso predicamento, pero no deja de ser fértil.

Los principales valores de la modernidad son la igualdad, la libertad, el pluralismo, la dignidad bumana, la paz y la solidaridad. Estos valores han tenido desiguales desarrollos en los ordenamientos constitucionales y en el Derecho internacional. La Constitución española de 1978 reconoce los principales valores superiores, a los que dota de eficacia jurídica, y que se desarrollan a través de principios y normas. En la Comunidad internacional los valores no han recibido un reconocimiento constitucional ni en la Carta de Naciones Unidas ni en el Derecho internacional general, pero no cabe duda de que hay desarrollos de estos valores en el marco de los principios fundamentales y estructurales del Derecho internacional.

Algunos valores, como la igualdad, están enraizados en el tejido del ordenamiento desde el Derecho internacional clásico, mientras que otros como la paz lo hacen en los inicios del Derecho internacional contemporáneo, y otros tan apenas han hecho presencia (como el de la libertad). Valores como el pluralismo o la solidaridad empiezan a entrar en el escenario jurídico internacional, de manera marginal. Estos valores son nociones abstractas que permiten sintetizar el sentido de los principios jurídicos y de las normas en que se desarrollan, que sirven de horizonte normativo como marco para el desarrollo.

En este sentido el valor de la solidaridad inicia su camino en la Comunidad internacional en los años cincuenta y sesenta, en el marco del conflicto norte sur y de la aparición de la cooperación al desarrollo. Desde los años sesenta del siglo XX empieza la preocupación por el desarrollo, con la creación de la Conferencia de Naciones Unidas sobre comercio y desarrollo (CNUCED), las reformas del GATT, la aparición del sistema de preferencias generalizadas, así como de la ayuda al desarrollo alimenticia, técnica, etc. Además empiezan a funcionar organismos especializados de Naciones Unidas con la vista puesta en el desarrollo y algunos Estados inician sus políticas y planes de cooperación para el desarrollo. En este marco algunos autores, con el tiempo, se refieren al principio de cooperación internacional, vinculado al desarrollo, como un principio estructural y/o constitucional del Derecho internacional. Algunos consideran que es un principio emergente, mientras que para otros está en formación. Hoy en día ya no solo constituye un principio político sino que tiene dimensiones jurídicas, dada la importante práctica internacional que se ha desarrollado.

No se podría afirmar, sin embargo, que el denominado principio de desarrollo sostenible es ya un principio constitucional y/o estructural del Derecho 
internacional. En esta línea el prof. Díaz Barrado indica que es pronto para concebirlo como un principio autónomo ${ }^{27}$. No es sencillo abordar la naturaleza del desarrollo sostenible pues está en cambio, es nuevo, y tiene características propias y muy específicas. Por ello autores como Rodrigo ${ }^{28}$ abordan la naturaleza del desarrollo sostenible en una perspectiva más amplia, tanto como objetivo político ${ }^{29}$ que como noción jurídica.

En su dimensión jurídica a su vez tendría una pluralidad de manifestaciones en su cada vez mayor creciente valor normativo. En primer lugar el desarrollo sostenible sería un principio jurídico internacional, indica. Pero, como ya hemos indicado, la doctrina está dividida en cuanto a los rasgos de este principio, bien sea sustantivo (de la que derivaría una obligación de resultado) o procedimental (mero proceso). Además Rodrigo reflexiona sobre la posible naturaleza del desarrollo sostenible como un concepto jurídico de naturaleza intersticial ${ }^{30}$, es decir, que no regularía tanto la conducta de los sujetos ni se dirigiría a ellos, sino que operaría entre normas primarias con el objetivo de modificar el alcance y efectos de aquellas y de establecer nuevas relaciones entre ellas; también analiza el desarrollo sostenible como una norma primaria de la que derivan obligaciones de comportamiento y como un derecho humano. Pero, fundamentalmente y con buen criterio este autor considera el desarrollo sostenible como un marco metodológico para la creación y la aplicación de políticas públicas y de normas jurídicas internacionales ${ }^{31}$; proporciona así un conjunto de herramientas, que ayuda a adoptar decisiones, que se refieren al discurso, la argumentación, el análisis, el fondo, el proceso y la interpretación que pueden contribuir a sintetizar, relacionar, fertilizar, armonizar e integrar los diferentes aspectos vinculados con el objetivo, que se pueden incorporar en los procesos de elaboración y aplicación de las políticas públicas y de las normas jurídicas internacionales.

27 Díaz BarRado, C., «Susteinable development goals: A principle and several dimensions», International society and the susteinable development goals, Chairo on development and poverty eradication URJC and SDG-Fund, Thomson Reuters, en prensa, 2016.

28 Rodrigo, A. J., El desafío del desarrollo sostenible, Tribuna Internacional, op. cit., p. 68 ss

29 Tal y como aparece, por ejemplo en la Estrategia española de desarrollo sostenible, aprobada por el Consejo de Ministros el 23 de noviembre de 2007; o en instrumentos internacionales como el preámbulo del Convenio sobre diversidad biológica, de 1992, la convención marco de las Naciones Unidas sobre el cambio climático (1992) y el protocolo de Kioto de 1997, la Convención de las Naciones Unidas sobre la desertificación de 1994 y el Protocolo de Cartagena sobre seguridad de la biotecnología del convenio sobre la diversidad biológica de 2000.

30 Rodrigo, A. J., El desafío del desarrollo sostenible, op. cit., p. 73.

31 Vid. Rodrigo, A. J., El desafío del desarrollo sostenible, op. cit., pp. 76 ss. 
Como vemos no es sencillo decantarse sobre la naturaleza del desarrollo sostenible, que supera los esquemas jurídicos clásicos. La novedad del fenómeno dificulta su encuadramiento en el mundo de las naturalezas jurídicas

\section{d) La gobernanza del desarrollo sostenible en la globalización}

Desde la caída del muro la sociedad internacional aparece como la sociedad de la incertidumbre ${ }^{32}$. El paso de un orden a un nuevo orden está pasando por el desorden. La globalización ha estado emparentada más con la economía, en una perspectiva neoliberal, que con los derechos u otros valores. La globalización es un término anglosajón con connotaciones distintas a la universalización y a la mundialización, y no ha sido un concepto portador de valores ni propicio como espacio para la política, al haberse ensanchado el espacio económico sin una ampliación del espacio político, habiéndose producido una sustitución de la razón política por la razón técnica ${ }^{33}$.

Indicaba Kofi Annan -Nosotros los pueblos. El papel de las Naciones Unidas en el siglo XXI- que la tarea principal en el siglo XXI consiste en asegurar que la mundialización sea una fuerza positiva para toda la población mundial, en lugar de dejar a millones de personas en la miseria. Stiglitz veía luz al final del túnel -Otro mundo. Contra el fanatismo del mercado- ${ }^{34}$ donde mantiene que el problema es la gestión no democrática de la globalización. Fontana en su reflexión sobre la crisis de comienzos del siglo XXI, considera que desde hace décadas se ha favorecido a los intereses de los más ricos, de las grandes empresas y de la especulación financiera. La sesgada recuperación de la economía estaría sirviendo para destruir algunas de las viejas conquistas sociales, privatizar la política y finalmente el propio Estado, lo que exige una restricción de las libertades democráticas, fundamentalmente en EEUU. Las políticas de austeridad, indica, han deteriorado la situación de los derechos en Europa y, globalmente, las consecuencias son un mundo de pobreza y conflicto ${ }^{35}$.

32 Dupuy, R. J., L'humanité dans l'imaginaire des nations, Collège de France, Julliard, 1991, p. 122.

33 DE VEGA, P., «Mundialización y derecho constitucional: la crisis del principio democrático en el constitucionalismo actual», REP, abril/junio de 1998.

34 Stiglitz, J.E., Un autre monde. Contre le fanatisme du marché, Fayard, París, 2006, pp. 37, 58 y 67.

35 FOnTANA, J., El futuro es un país extraño. Una reflexión sobre la crisis social de comienzos del siglo XXI, Pasado\&Presente, Barcelona, 2013, 230 pp. 
El valle de lágrimas de la globalización, en expresión de Habermas, parece deslegitimar un orden sometido a los dictados del mercado, convertido en instrumento de realización de sus objetivos. Esta situación no es buena ni para el desarrollo sostenible ni para los derechos humanos.

Tampoco lo es el fenómeno del desdoblamiento del mundo ${ }^{36}$ en el sentido de que junto al mundo de las Instituciones, de la legalidad, de las Organizaciones internacionales y de los Estados aparece un mundo de fuerzas vivas, en particular en este caso de empresas multinacionales y mercados. Y esto se ha hecho sin una transformación de la arquitectura jurídico política internacional que pueda organizar la globalización, ni la desterritorialización del derecho ni el nuevo mundo digital en que se desarrolla la vida internacional y nacional. Fenómenos todos ellos nuevos que se añaden a otros más conocidos como el debilitamiento del Estado o la globalización económica. Algunos pronosticaron la vuelta a la Edad Media, en expresión de Alan Minc, a un mundo sin referencias de autoridad. Otros predicen el declive irreversible del Estado social y del modelo social europeo. Algunos describen una nueva ley de la selva.

Por ello no corren buenos tiempos para los derechos bumanos y el desarrollo, pues no están en el centro de la Agenda internacional. De allí que la Agenda 2030 sea positiva pues, con independencia de sus grandes debilidades, intenta dirigir la mirada y el debate hacia objetivos solidarios y de promoción de los valores. Hay que evitar ser profetas de catástrofes, que solo auguran desgracias. El mundo se mueve desde siempre entre avances y retrocesos, entre luces y sombras. En este sentido el desarrollo sostenible es una idea fuerza que puede evitar que se pierda el tesoro de los derechos humanos que tanto costó construir en la Comunidad internacional del siglo XX.

Hacer posible el desarrollo sostenible en el marco de la globalización no es tarea sencilla pues, como indicase el Secretario General de Naciones Unidas, en 2005 -Un concepto más amplio de la libertad: desarrollo, seguridad y derechos bumanos para todos- en ocasiones lo acordado por la Comunidad internacional son palabras huecas ${ }^{37}$. Esto requiere transformaciones institucionales y normativas, que permitan humanizar y gobernar la globalización ${ }^{38}$.

36 La expresión es de Dupuy, R.J., «Le dédoublement du monde», RGDIP (1996/2), p. 320.

37 Informe del Secretario General de Naciones Unidas, Kofi Annan, de 21 de marzo de 2005, párrs. 128-131.

38 Vid. CaRrillo Salcedo, J.A., Globalización y orden internacional, Lección inagural de la Universidad de Sevilla, curso 2004-2005, p. 25; FARIÑAS DUlCE, M.J., Globalización, ciudadanía y derechos humanos, Instituto de derechos humanos Bartolomé de las Casas, Dykinson, 2000, 60 
Es necesaria una nueva gobernanza mundial. En su día la proliferación de Organizaciones internacionales modificó la estructura de la sociedad internacional, como pusieron de manifiesto autores como Reuter, Friedmann o Dupuy. Se superó la fase de coexistencia entre Estados y empezó nueva fase de cooperación internacional, que dio lugar a un modelo institucional de sociedad internacional, que convive con el modelo interestatal, que no desaparece. Desde la globalización se ha producido un cierto debilitamiento de las Organizaciones internacionales y fenómenos de fragmentación institucional, a pesar de la proliferación de Instituciones internacionales. El debilitamiento del Estado no ha producido un correlativo reforzamiento de las Instituciones internacionales. En el actual momento de la vida internacional ha proliferado el soft law y las soft institutions en el denominado global law. Tanto término anglosajón responde a la gobernanza, término vinculado al proceso neoliberal.

La sociedad internacional del siglo XXI debe gestionar el debilitamiento del Estado y la crisis del modelo de Estado nación, la globalización y la crisis del modelo social, el reforzamiento de la sociedad civil sin cauces adecuados de participación, el reforzamiento de los grupos informales en la sociedad internacional y la sociedad digital. Esa arquitectura internacional deriva de la segunda guerra mundial, y no está a la altura de los retos de fondo, en cuanto al medio ambiente, la economía, la ecología, los derechos humanos, la solidaridad, la gestión de los conflictos, la paz y el desarrollo sostenible, entre otros.

A día de hoy hay unos renovados objetivos de la Comunidad internacional, con los ODS, que sin embargo, carecen de una arquitectura renovada. El Secretario general de Naciones Unidas impulsó la Red de soluciones de desarrollo sostenible ${ }^{39}$, que asesoró en la creación de los ODS, que luego dio lugar a las negociaciones intergubernamentales. En la actualidad el marco institucional para la gobernanza del desarrollo sostenible no está a la altura del desafío. La Conferencia de 2012 puso de relieve la necesidad de debatir sobre la gobernanza reformando las instituciones que participan en la aplicación del programa de desa-

pp.; FeYTER, K. DE, «Globalization and human Rights», International buman Rights law in a global context, Gómez Isa, F., Fester, K. DE (eds.), Universidad de Deusto, Bilbao, 2008, pp. 51 96. FernándeZ Tomas, A., Las estructuras de cooperación para el desarrollo en las Naciones Unidas, Valencia, 1987; GONZÁLEZ GARCía, I., Naciones Unidas y la coordinación para el desarrollo, Dykinson Madrid, $361 \mathrm{pp}$.

39 SACHS, J., La era del desarrollo sostenible, op. cit., p. 563. 
rrollo sostenible del sistema de Naciones Unidas, en particular la Comisión sobre el Desarrollo sostenible y el Programa de Naciones Unidas sobre medio ambiente; además que habría que reformar las Instituciones sobre desarrollo sostenible.

La arquitectura institucional del desarrollo sostenible está necesitada de una renovación. Sigue trabada por un conjunto de Conferencias internacionales, así como por órganos del sistema de Naciones Unidas como la Comisión sobre el desarrollo sostenible, que se creó en 1992 para hacer el seguimiento de la Conferencia de Naciones Unidas sobre el Medio ambiente y el desarrollo y, posteriormente, del Plan de aplicación de las decisiones de Johannesburgo, desde la Cumbre de desarrollo sostenible de 2002. Integrada por 53 miembros, es en el sistema ONU la que impulsa el desarrollo sostenible e impulsa políticas y promueve alianzas. Desde 2002 también se han hecho más de 360 asociaciones para el desarrollo sostenible, de naturaleza público-privadas. Además también es relevante el Comité ejecutivo de asuntos económicos y sociales así como iniciativas como ONU-Agua, ONU-energía y ONU-Océanos. A nivel regional las comisiones regionales han impulsado acciones, planes de desarrollo y estrategias, sobre todo de lucha contra la pobreza. Desde la perspectiva ambiental desde los años setenta se han fortalecido las Instituciones, como el PNUMA, y las Instituciones nacionales y ONGs. En el marco medioambiental hay una mayor fortaleza institucional que en el marco económico, cuyas instituciones siguen siendo las de postguerra y que en el pilar social. Ahora bien, en realidad todavía no existe, por ejemplo una Organización internacional internacional del medio ambiente que aborde una cuestión tan compleja de manera integral, por lo que hay una proliferación de órganos y de normas dispersas, con miles de instrumentos, lo que es muy difícil de gestionar en una sociedad descentralizada.

En todo caso habría que ir hacia una arquitectura internacional del desarrollo sostenible a la altura del desafío, lo que en la actualidad no existe, tanto en el marco de las Naciones Unidas, como de otras Instituciones internacionales. Es cierto que se ha propuesto una Alianza Mundial para el desarrollo sostenible revitalizada, con el apoyo de medidas de financiación para el desarrollo, adoptadas por la Tercera Conferencia internacional sobre la financiación para el desarrollo (agenda de acción de Addis Abeba), aprobada por la Asamblea General el 27 de julio de 2015 (Res. 69/313, anexo), entre otras medidas. Pero falta una arquitectura internacional para el desarrollo sostenible de envergadura. De ahí que haciendo de la necesidad virtud Naciones Unidas ponga el acento en la responsabilidad de los gobiernos en el cumplimiento de 
los ODS durante los próximos quince años. A tal efecto se están elaborando indicadores para seguir y controlar a los gobiernos sobre la base de los avances en lograr los objetivos.

\section{Transformaciones Para El Derecho INTERnaCional}

\section{a) Una transformación de los objetivos}

Los ODS plantean asimismo cuestiones desde la propia concepción del Derecho internacional. Inicialmente, en tanto que función mínima, el Derecho internacional tiene, como dijera Kelsen, la función mínima de repartir las competencias entre los Estados (las esferas de validez de los ordenamientos estatales). La introducción de objetivos para todo el sistema jurídico en su conjunto, para el Derecho internacional, no es algo nuevo en la Comunidad internacional, aunque sí lo es la forma en que se está haciendo.

No es nuevo, pues es una vieja técnica, que ha estado vinculada al derecho internacional de los derechos humanos y, más recientemente, al derecho internacional del desarrollo. Autores como Dupuy ${ }^{40}, \mathrm{Mahiou}^{41}$ o Carrillo Salcedo ${ }^{42}$ han concebido el Derecho internacional como un derecho de finalidades, comprometido por el cambio. Para Dupuy el derecho situacional tiene la especificidad en su finalidad, mientras que Mahiou se refería al derecho comprometido (en cuanto al derecho al desarrollo). Más recientemente, Carrillo Salcedo indicaba que la «insuficiencia del antiguo Derecho internacional y la necesidad de un nuevo Derecho internacional que, para estar a la altura de sus funciones (...) debe afrontar la puesta en marca de un orden comunitario adoptado a las dimensiones del planeta cuyo objetivo primordial e inmediato sea la promoción equilibrada y armónica del desarrollo de toda la humanidad considerada como un conjunto».

En este sentido, en la sociología del Derecho los funcionalistas intencionalistas analizan las finalidades a las que se orienta un sistema. Desde el derecho

40 Vid. Dupuy, R. J., «Droit international et disparités de développement. Cours général de droit international public», RCADI (1979-IV), t. 165, pp. 120 ss.

41 Vid. también sobre las finalidades (en el ámbito de las fuentes, la revisión de las instituciones y de los principios y normas) del Derecho internacional del desarrollo, MAHIOU, A., «Droit international et développement», en Cardona, J. (dir.), Cursos euromediterráneos Bancaja de Derecho internacional, vol. III, 1999, Aranzadi, 2000, pp. 29-140, en especial pp. 34-40, pp. 35-36.

42 Cfr. Carrillo Salcedo, J.A., «Permanence et mutations en droit international», Boutros Boutros Ghali. Amicorum discipulorumque Liber, Bruylant, Bruxelles, 1998, p. 300. 
autores como Duguit o Scelle, hace un siglo, analizaban el derecho desde las necesidades sociales (objetivistas) superando el iuspositivismo del siglo XIX, por la preocupación social. En el siglo Xx los normativistas han sido superados por los internacionalistas como Visscher ${ }^{43}$, Friedmann ${ }^{44}$, Thierry ${ }^{45}$, R.J. Dupuy, P. M. Dupuy o J.A. Carrillo Salcedo. Estos autores conciben el Derecho internacional desde su función transformadora de la sociedad internacional, superando el relativismo axiológico y el formalismo. Esto no significa entender el Derecho internacional sólo desde una perspectiva ética y finalista, como criticaba D. Kennedy ${ }^{46}$. Pero también es cierto que ciertos proyectos y compromisos van generando el caldo de cultivo necesario para las propuestas de reforma frente a los problemas comunes.

El Derecho al desarrollo ha sido calificado tradicionalmente como un orden finalista y teleológico, orientado a una misión (derecho para el desarrollo). Así lo enfocan autores como Bollecker-Stern ${ }^{47}$, Gros Espiell, Touscoz, Flory, Pellet, Pelaez Marón, Bennouna, Slinn, Bouveresse, Mahiou, Mbaye ${ }^{48}$, Bermejo ${ }^{49}$

43 VissCHER, C., Teorías y realidades en derecho internacional público, Bosch, Barcelona, 1962, pp. 135 y 141 .

44 FriedmanN, W., «Droit de coexistence et droit de cooperation. Quelques observations sur la structure changeante du droit international», pp. 1 y ss. y 9.

45 ThIERry, H., «Internationalisme et normativisme en droit international», Guy de Lacharrière et la politique juridique extérieure de la France, Masson, París, 1989, p. 371. «L'évolution du droit international. Cours général de droit international public», RCADI (1990-III), 222 pp., pp. 17-19

46 Kennedy, D., Rompiendo moldes en el Derecho internacional: Cuando la renovación es repetición, Cuadernos internacional 3, Universidad Autónoma de Madrid, traducción y prólogo de Ignacio Forcada, Dykinson, 2002, en especial. pp. 27-30.

47 Bollecker-Stern, B., «Le droit international du développement: un droit de finalité», $L a$ formation des normes en droit international du développement, Flory, M., HeNRY, J., CNRES, 1984; Gros EspielL, H., «El derecho al desarrollo veinte años después: Balance y perspectivas», Reflexiones tras un año de crisis, VV.AA., Universidad de Valladolid, 1996, pp. 27-59, p. 32; TouscOZ, J., «Les Nations Unies et le droit international économique. Rapport introductif», Les Nations Unies et le droit international économique, SFDI, VV.AA., Pedone, París, 1987, p. 16; Flory, M., Droit international du développement, Puf, París, 1977; Feuer, G. y Cassan, H., Droit international du développement, Dalloz, 2a ed., 1991; PELlET, A., Droit international du développement, Que sais-je?, 1731, Puf, París, 2ª ed., 1987; BennounA, M., Droit international du développement, Berger-Levrault, 1982; SNYDER, F. y SLInN, P., International law of developpement, Londres, 1987; Bouveresse, J., Droit et politique du développement et de la coopération, Puf, 1990.

48 Vid. MваYE, K., «Le droit au développement en droit international», Essays in international law in honour of judge M. Lachs, Martinus Nijhoff Publishers, 1984, pp. 163-177, p.163.

49 Bermejo. Vers un nouvel ordre économique international. Etude centrée sur les aspects juridiques, Editions Universitaires Fribourg Suisse, 1982, p. 15 y 16. 
o Gutiérrez Espada ${ }^{50}$ o Colliard ${ }^{51}$. El desarrollo sostenible debe ser visto en esta misma orientación clásica, lo que no deja de tener un aspecto mítico-utópico.

Los objetivos de un orden jurídico tienen relación con la concepción del Derecho como un derecho reivindicativo ${ }^{52}$, en el cual juega un papel la noción de mito y utopía, así como el derecho suave y el derecho en agraz. El mito del desarrollo, indicaba R.J. Dupuy ${ }^{53}$ está al servicio de una idea-fuerza y movilizadora. Las utopías, a diferencia de los mitos -que sintetizan en el discurso jurídico una realidad normativa - se sitúan más en el ámbito de la lege ferenda y sirven a la función ideológica del Derecho internacional. Utilizamos el término utopía en el sentido de proyecto a realizar en el Derecho internacional, siendo un motor para la transformación, para el cambio normativo ${ }^{54}$. Una utopía define los horizontes de cambio normativo, normalmente en defensa de los débiles y de valores de realización de la justicia. El pensamiento utópico construye sociedades ideales, es decir, que todavía no se han realizado, lo que no significa que sean irrealizables ${ }^{55}$.

En este sentido el desarrollo sostenible forma parte de la utopía de la Comunidad internacional contemporánea. La utopía no nos debe situar al margen de una visión socio-histórica o real del ordenamiento, pero un exceso de realismo puede ser negativo, porque lo que parece utópico hoy puede ser posible en el futuro. No se puede ni pensar ni construir el mundo desde modelos utópicos desconectados y alejados de la realidad. No debemos ponernos unas gafas coloreadas de Walt Disney ${ }^{56}$. Pero no hay que olvidar que algunos visionarios (o algunas visiones) del pasado contribuyeron a hacer avanzar las cosas. El Derecho internacional se ha enriquecido por conceptos e ideas que han orien-

50 GUTIÉRREZ EsPadA, C., «Sobre las funciones, fines y naturaleza del derecho internacional contemporáeo», Homenaje al Prof. Mariano Hurtado Bautista, 1992, p. 69.

51 Colliard, C.A., «Spécificité des Etats. Théorie des status juridiques particuliers et d'inégalité compensatrice», Mélanges offerts à Paul Reuter. Le droit international: unité et diversité, Pedone, París, 1981, pp. 153-180, p. 180.

52 Cfr. PÉREZ GONZÁLEZ, M., «El derecho al desarrollo como derecho humano», El derecho al desarrollo o el desarrollo de los derechos, Ed. Universidad Complutense, VV.AA., p. 96; FLORY, M., «La politique juridique extérieure et le nouvel ordre économique international», Guy de Lacharrière et la politique juridique extérieure de la France, De. Masson, 1989, París, 158-266, p. 265.

53 Dypuy, R.J., La clôture du système international. La cité terrestre, Puf, París, 1989, p. 31.

54 En este sentido Dypuy, R.J., «Droit, révolution, utopie», Révolution et Droit international, p. 435; FRANCK, T., «Legitimacy in the international system», AfIL (1988/4), pp. 705-759.

55 Ramiro Aviles, M.A., Utopía y derecho. Análisis de la relación entre los modelos de sociedad ideal y los sistemas normativos, Tesis doctoral, Universidad Carlos III de Madrid-Instituto de Derechos Humanos Bartolomé de las Casas, Getafe, abril de 2000, 779 pp. y p. 18.

56 LaCHS, M., Le monde de la pensée en droit international, p. 18 
tado las acciones políticas, realizado proyectos e Instituciones internacionales y que, finalmente, se han encarnado en el Derecho positivo ${ }^{57}$.

En la historia del Derecho internacional muchas utopías del pasado se reflejan en los principios y las normas el Derecho internacional del tiempo presente. Dreyfus ${ }^{58}$ comparó las imágenes doctrinales del Derecho internacional a finales del siglo XIX y las realidades del siglo XX, llegando a la conclusión de que muchas de las aspiraciones utópicas de la doctrina se convirtieron en realidad o, al menos, hicieron avanzar las cosas. Por ejemplo, la utopía de la codificación, de la jurisdicción internacional obligatoria, de la existencia de Tribunales internacionales, de Organizaciones internacionales, de la utopía federalista o de la unión europea. Estas utopías orienta la evolución jurídica desde ideas fuerza, conceptos y visiones ${ }^{59}$. Hoy en día sería la utopía del desarrollo sostenible.

La mitificación de ciertos conceptos tiene relevancia porque en ocasiones acaban penetrando en el sistema normativo. Ciertos símbolos míticos e ideales -algunos de ellos valores- tienen una gran potencia metafórica que contribuye a reafirmar los valores que subyacen en el sistema jurídico, y a transformar ideológicamente el contenido de sus principios y reglas: la paz universal, la democracia o la misma humanidad abstracta ${ }^{60}$. Aquí entra en juego el poder de las palabras, que son el tejido del ordenamiento.

Hay que tener precaución sobre las virtudes de los mitos metafóricos en el marco de la creación del Derecho, porque pueden conducir a perder de vista el objetivo normativo de una negociación, favoreciendo la imprecisión y la vaguedad terminológica. En todo caso, la legitimité annonciatrice $e^{61}$,

57 La utopía tiene un papel más importante en el Derecho internacional del que, normalmente, se le atribuye. Cumple funciones sobre todo en relación con la lex ferenda, negando y rechazando reglas, afirmando otras y anticipándose al futuro, siendo una característica frecuente de la utopía, como señala Serge Sur, el referirse a un derecho trascedente, absoluto, y no producir sino un derecho coyuntural. Vid. SUR, S., «Système juridique international et utopie», Archives de philosophie du droit, t. 32, Le droit international, Sirey, 1981, pp. 35-45.

58 DREYFus, S., «D'un siècle à l'autre: Remarques sur l'image du droit international public», Boutros Boutros Ghali Amicorum discipulorumque Liber. Paix, Développement, démocratie, Bruylant, Bruxelles, 1998, pp. 359 ss.

59 NAfZIgER, A. R., «The functions of religion in the International system», The influence of religion on the development of International law, cit., 1991, pp. 149 ss, p. 151.

60 CAHIN, G., «Apport du concept de mythification aux méthodes d'analyse du droit international», Le droit des peuples à disposer d'eux-mêmes. Méthodes d'analyse du droit international. Mélanges offerts à Charles Chaumont, Pedone, París, 1984, pp. 89-115, p.92.

61 Vid. sobre esto Dupuy, R. J., La Communauté internationale entre le mythe et l'histoire, Economica, París, 1986, pp. 119, 120. 
como idea de adecuación del Derecho a la justicia, se ha manifestado en múltiples ocasiones en la AGONU, contribuyendo a transformar la legalidad. Por ejemplo, el Nuevo orden económico internacional fracasó en sus aspiraciones maximalistas, pero los mitos y las utopías contribuyeron, a pesar de algunas desilusiones, a transformar en un sentido solidario el Derecho internacional.

Por lo tanto, el Derecho internacional también se desarrolla con referencia a mitos universales que, en ocasiones, se encarnan en el sistema normativo, al menos parcialmente. La utopía invoca el cambio normativo, normalmente en interés de los sujetos más débiles en el ordenamiento, o de intereses generales, como sucede en relación con la noción de desarrollo sostenible. De tal modo que las utopías otorgan al Derecho una dimensión ideológica que proyecta representaciones y referencias intelectuales y morales, que se añaden a su dimensión organizativa y de registro (S. Sur). En este sentido cabe pensar que, como indica Sur, en su dimensión utópica el Derecho internacional es de los débiles, que tiende o debe tender a compensar y corregir las desigualdades, en su dimensión organizativa es un derecho de iguales y en su dimensión de registro es un derecho de los poderosos, que consagra de manera general su situación y sus ventajas ${ }^{62}$.

Algunos ámbitos del Derecho internacional son tributarios de aproximaciones utópicas, como ocurre con el Derecho internacional del desarrollo, el derecho internacional de los derechos humanos o de la probibición del uso de la fuerza y el establecimiento del sistema de seguridad colectiva. La Declaración universal de 1948 estableció un horizonte utópico ${ }^{63}$. En la actualidad los denominados derechos de tercera generación simbolizan nuevas utopías. La utopía de la paz a través del Derecho ha sido compartida y ha dado lugar a múltiples proyectos de paz, a la creación de la Sociedad de Naciones y de Naciones Unidas ${ }^{64}$. La Carta de las Naciones Unidas tiene así una doble dimensión jurídica y utópica (programática, ideológica, casi religiosa), como texto normativo constitucional, de un lado, e ideológico-político, de otro, donde se pretende el ideal de la paz por el derecho ${ }^{65}$. La utopía sirve

62 SuR, S., «Sistème juridique international et utopie», Archives de philosophie du droit, t. 32, Le droit international, Sirey, 1987, p. 41.

63 Carrillo Salcedo, J. A., Dignidad frente a la barbarie. La declaración universal de derechos humanos, cincuenta años después, Minima Trotta, Madrid, 1999, p. 26.

64 Goyard-Fabre, S., La construction de la paix ou le travail de sisyphe, Vrin, 1994, pp. 225 ss.

65 Dupuy, P. M., «L'enfer et le paradigme: libres propos sur les relations du droit international avec la persistance des guerres et l'objectif ideal du maintien de la paix», Mélanges H. Thierry. L'évolution du Droit international, Pedone, París, 1998, pp. 186-199, en especial 188, 191 a 194. 
para orientar el camino, aunque sólo se hace camino al andar ${ }^{66}$. La nueva utopía del siglo XXI es la del desarrollo sostenible.

En el pasado frente al mito de la paz por el Derecho se oponía el de la ineficacia absoluta del Derecho internacional o al mito del estado de naturaleza se oponía el de la paz por un poder superestatal ${ }^{67}$. Del mismo modo constituye un mito reaccionario la concepción mítica, mística e hiperbólica de la soberanía como noción absoluta, que conduce a negar la existencia del Derecho internacional. En los últimos tiempos frente al mito de la ideología del desarrollo prevalece el mito del desarrollismo ${ }^{68}$, el crecimiento como principio justificador de una globalización asimétrica. Ha sido ésta una utopía reaccionaria, que se está empezando a contrarrestar con el proyecto del desarrollo sostenible. La utopía del desarrollo sostenible no debe por ello ser visto como algo irrealizable, sino como un proyecto de realización progresiva.

\section{b) Una transformación del marco normativo internacional}

El desarrollo sostenible está siendo un ámbito especialmente propicio para el soft law, lo que no significa que el hard law sea irrelevante o no exista. Es cierto que no se debe confundir el Derecho con lo que no es Derecho. Indicaba Weil ${ }^{69}$ que existe una doble crisis de la normatividad internacional, al debilitarse el Derecho internacional en su inflación y al aparecer inciertas super-normas (el ius cogens).

En este sentido la difuminación de la juridicidad de las normas que puede generar el discurso utópico se hace desde la confusión entre las aspiraciones y la evolución del Derecho, entre el imaginario y la realidad, como sucedió con el $\mathrm{NOEI}^{70}$, que constituyó fundamentalmente una referencia del derecho deseable (en agraz, soft law), pero no al Derecho positivo (hard law) ${ }^{71}$. Pero como

66 Pons Rafols, X., «La participación de España en el sistema de acuerdos de fuerzas de reserva de las operaciones de mantenimiento de la paz», Agenda $O N U, \mathrm{n}^{\circ} 2,1999$, pp. 123-164, p. 147.

67 Vid. sobre estos mitos y sus contra-mitos DUPUY, R.J., «L'illusion juridique. Réflexions sur le mythe de la paix par le droit», Guy de Lacharrière et la politique juridique extérieure de la France, Masson, París, 1989, pp. 245-257, p. 252.

68 DE VEGA, P., «Mundialización y derecho constitucional. La crisis del principio democrático en el constitucionalismo actual», Revista de estudios politicos (abril/junio, 1998), pp. 13 ss, p. 16.

69 WEIL, P., «Le droit international en quête de son identité», RCADI, cit. pp. 227 ss.

70 Bennouna, M., «Réalité et imaginaire en droit international du développement», Le droit des peuples à disposer d'eux-mêmes. Méthodes d'analyse du droit international. Mélanges offerts à Charles Chaumont, Pedone, París, 1984, pp. 59-72, p. 67.

71 Sobre esto véase el trabajo ya citado del Profesor Romualdo Bermejo, sobre el NOEI. Además, PELlet, A., «Le «bon droit» et l'ivraie - Plaidoyer pour l'ivraie (Rémarques sur quelques 
hemos señalado en el epígrafe anterior no hay que olvidar que la utopía juega un papel en la lex ferenda cuando reivindica el cambio del Derecho, la modificación de la lex lata, como sucede con el Derecho internacional del desarrollo sostenible.

El soft law juega un papel relevante en la interpretación del derecho positivo, en la transformación progresiva de su contenido, en el comportamiento de los sujetos y en la transformación de la opinio iuris ${ }^{72}$. El soft law es importante porque evidencia la transformación constante del Derecho internacional y su evolución. En el desarrollo progresivo del Derecho internacional del desarrollo sostenible la transformación del soft law en hard law es asimismo importante. Hay instrumentos en la cuestión Empresa-Derechos humanos que tienen una vocación meramente voluntaria, o no obligatoria. Así, el Pacto Mundial se concibe como una iniciativa voluntaria en la cual las empresas se comprometen a alinear sus estrategias y operaciones con diez principios universalmente aceptados en cuatros ámbitos: derechos humanos, estándares laborales, medio ambiente y corrupción. En esta iniciativa hay 12000 participantes de 145 países. Pero el Pacto mundial no genera obligaciones jurídicas, no se concibe como un control a las empresas, no genera estándares exigibles ni regímenes para las empresas. Participar en el Pacto mundial implica un compromiso visible de las empresas para introducir los principios en su gestión, publicar en el informe anual una descripción de las acciones y apoyar públicamente el pacto mundial y sus principios.

Este tipo de iniciativas son bienvenidas como punto de partida, pero indudablemente insatisfactorias como punto de llegada. De ahí la necesidad, en nuestra opinión, de que se produzca un desarrollo progresivo del Derecho internacional en la cuestión de las empresas y los derechos humanos.

problèmes de méthode en droit international du développement), Le droit des peuples à disposer d'eux-mêmes. Méthodes d'analyse du droit international. Mélanges offerts à Charles Chaumont, Pedone, París, 1984, pp. 465-525, p. 470. Reisman, M., «The concept and functions of soft law in international politics», Essays in honour of judge Raslim Olawale Elias, vol. 1. Contemporary international law and human rights, Bello, E., San, A., Edit, Martinus Nijhoff Publishers, 1992, pp. $135-144$, p. 144

72 Bothe, M., «Legal and non legal norms: A Meaningful existence of non-binding agreements», NYIL (1977-1980), pp. 65-95; SCHACHTER, O., «The twilight existence of non binding agreements», AfIL (1977), pp. 294-304 CHINkIN, C., «The challenge of soft law», ICLQ (1989), pp. 850-866; EISEMANN, P. M., «Le gentlement's agreement comme source du Droit international», FDI (1979), pp. 326-348; VIRALLY, M., «La distinction entre textes internationales de portée juridique et textes internationaux dépourvues de portée juridique», Annuaire de l'Institut de DI (1983), pp. 166 ss. 
En esta línea sería conveniente que tuviese éxito la iniciativa que tuvo el Consejo de Derechos humanos, mediante la Resolución 26/9, de junio de 2014, de elaborar un instrumento jurídicamente vinculante para regular, en el Derecho internacional de los derechos humanos, las actividades de las corporaciones transnacionales $y$ de otras empresas ${ }^{73}$.

La iniciativa que llevó a la Res. 26/9 fue auspiciada por Ecuador, Sudafrica, Bolivia, Cuba y Venezuela y apoyada por unas seiscientas organizaciones de la sociedad civil. Pero la propuesta no obtuvo el consejo, pues en el Consejo de Derechos humanos recibió el apoyo de 20 Estado, y la oposición de 14, entre otros de Estados Unidos y los Estados miembros de la Unión Europea, mientras que otros 13 Estados se abstuvieron ${ }^{74}$.

Desde los primeros debates del grupo de trabajo se vislumbran algunos problemas que pueden obstaculizar un Tratado en la materia. Desde la noción de empresa, o al ámbito de actividades y actores cubiertos por el Tratado, o los derechos humanos que serían tenidos en cuenta o al carácter de las obligaciones que tendrían las empresas, son entre otras, algunas de las dificultades que se han planteado.

Pero avanzar en esta materia no es tarea sencilla, por diversas razones. Las empresas transnacionales operan en un contexto de debilitamiento del Estado en el que el escenario es de escaso desarrollo de las reglas internacionales. Humanizar la globalización exige desarrollar controles sobre los no-sujetos (como las empresas), impulsar no solo la autoregulación sino disminuir la desregulación, y someter al derecho el mercado. Hay muchos elementos necesitados de aclaración, como la existencia de un marco normativo fragmentado en diversas Instituciones (Naciones Unidas, Unión Europea, OCDE, Organización internacional del Trabajo, tratados, Estados, autoregulación) y convenios así como en instrumentos internacionales de soft law. Esta dispersión normativa dificulta la identificación de un marco normativo en el que abunda el soft law.

De otro lado, avanzar se está haciendo mediante nuevos instrumentos, como son las estrategias nacionales e internacionales o los planes nacionales. Estos instrumentos son distintos a los clásicos Tratados internacionales, están

73 Vid. al respecto LOPEZ, C. y SHEA, B., «Negotiating a treaty on business and human rights: a Review of the first intergovernmental sesión», Businenss and buman rights journal, 1 (2015), pp. 111-116.

74 SChutTer, O. DE., «Towards a New Treaty on business and human rights», Business and human rights journal, 1 (2015), pp. 41-67. 
más en el ámbito del soft law, pero van generando una práctica internacional que progresivamente puede contribuir a modificar el marco normativo. En esta línea, aunque en España el borrador de Plan nacional de derechos humanos y empresas $^{75}$ se ha quedado paralizado, no ha sido así en otros países donde ya existen en países como Reino Unido, Holanda, Dinamarca, Finlandia, Lituano, entre otros. El grupo de Naciones Unidas sobre derechos humanos y empresas viene recomendando en los últimos años a los Estados que desarrollen Planes nacionales y United Nations Global Compact publicó en 2015 una guía, lo mismo que el Consejo de Europa un año antes. Mediante los mismos se pretende que los Estados desarrollen en el derecho interno los estándares internacionales en la materia. Estos plantes tienen sus pros y sus contras pues si bien impulsan que los Estados desarrollen sus compromisos en la materia tienen algunos problemas. Entre otros, que su ámbito, contenido y prácticas cubiertas sean muy restrictivas, o que la base de evaluación de las empresas no sea rigurosa y objetiva.

El seguimiento que se da a los avances en los ODS no concuerda con la filosofía del Derecho internacional. Como se indica en la Agenda 2030 para el Desarrollo sostenible los procesos de seguimiento y examen a todos los niveles se guiarán por el principio de ser de carácter voluntario ${ }^{76}$.

Del mismo modo cabe indicar que el progreso del Derecho internacional del desarrollo sostenible da lugar a la aparición de principios y reglas novedosos, muchos de los cuales hasta su consolidación viven un largo camino de peregrinaje del soft law al hard law. Buena prueba de ello es el análisis que realiza el profesor J. Rodrigo sobre los principios del derecho internacional relativos

75 Vid. sobre esto O’Brien, M.; Mehra, A.; Blackwell, S. y Poulsen-Hansen, C. B., «National action plans: Current Status and future prospects for a New business and human rights governance Tool», Business and human rights fournal, 1 (2015), pp. 117-126. Vid. sobre el Plan MÁrquez Carrasco, C., «El Plan nacional de España sobre empresas y derechos humanos y la implementación de los pilares de proteger, respetar y remediar: oportunidades y desafíos», España y la implementación de los principios rectores de las Naciones unidas sobre empresas y derechos bumanos: oportunidades y desafíos, VV.AA., Huygens, 2014, 790 pp., 25-53; sobre la práctica española, entre otros, en el mismo libro colectivo PIgRAU, A. y JARIA, J., «La aplicación de los principios rectores sobre empresas y derechos humanos en el caso de los daños al medio ambiente causados por empresas españolas en terceros países», pp. 303 ss.; en el mismo libro BELMONTE Aliaga, N., «The right to housing and the Spanish banking sector: implementing the UN guiding principles on business and human rights», pp. 473 ss.; MENDiola GonZalo, M., «Observaciones de Amnistía internacional sobre el plan nacional de empresas y derechos humanos», pp. 509 ss.; VIVAS TESON, I., «Algunas consideraciones sobre la reparación del daño por violación de los derechos humanos por la empresas transnacionales españolas», pp. 571 ss.;

76 Transformar nuestro mundo: La agenda 2030 para el desarrollo sostenible, op. cit., pár. 74. 
al desarrollo sostenible. Entre estos cabe destacar el principio de utilización sostenible de los recursos naturales, el principio de equidad intergeneracional e intrageneracional, el principio de responsabilidades comunes pero diferenciadas, el principio de precaución, el principio de participación pública y acceso a la información y la justicia, el principio de buena gestión de los asuntos públicos (good governances) y el principio de integración de los aspectos económicos, sociales y medioambientales del desarrollo sostenible ${ }^{77}$.

\section{c) Las transformaciones en los actores y sujetos del Derecho internacional}

Otro elemento preocupante para el desarrollo sostenible y los derechos humanos, es el fenómeno de la privatización que ha conducido asimismo a cambiar el papel de los sujetos de derecho internacional y de los actores de la sociedad internacional. Muchos de los diecisiete objetivos de desarrollo sostenible pueden realizarse si las empresas y otros actores contribuyen a ello. Pero con la expresión privatización, en el Derecho internacional, se quiere significar que competencias del Estado y servicios públicos que afectan directamente al goce de los derechos humanos son privatizados y realizados por actores no estatales, lo que incide y dificulta su realización. Han señalado los comités de derechos humanos de Naciones Unidas ${ }^{78}$ que la obligación del Estado de respetar y de promover los derechos incluye la obligación de velar por que los proveedores privados de servicios actúen de conformidad con sus disposiciones, por lo que hay obligaciones indirectas para esas entidades. Las obligaciones de los Tratados internacionales de derechos humanos vinculan a los Estados de manera directa, y no se genera el denominado efecto directo horizontal, pero el Estado solo cumpliría sus obligaciones internacionales si actúa de tal modo que se proteja a las personas frente a la acción o inacción por los particulares de tal manera que no se menoscabe el disfrute de los derechos ${ }^{79}$.

En este contexto la responsabilidad de las empresas es especialmente evidente. En Nuremberg ya se planteó la cuestión de las violaciones de derechos humanos por el trabajo forzado de los prisioneros, del que se veían beneficia-

77 Vid. sobre estos Rodrigo, J., El desafío del desarrollo sostenible, op. cit., pp. 95-191.

78 Observación general $n^{\circ} 5$, de 2003 sobre las medidas de aplicación de la convención sobre derechos del niño, de 27-XI-2003, pár. 42.

79 En este sentido Observación general n 31. Naturaleza de las obligaciones impuestas a los Estados por el Pacto, 26-V-2004, pár. 4. 
das las empresas ${ }^{80}$. En todo caso de la segunda guerra mundial sigue habiendo asuntos actuales relativos a la reparación de personas que fueron víctimas del holocausto, de lo que se aprovecharon diferentes tipos de empresas, como Bancos, compañías de seguros, empresas fabricantes, etc., lo que ha dado lugar a acuerdos de compensación global, y a indemnizaciones por medio de otras vías como Comisiones internacionales de reclamación (en compañías de seguros), compensación ex gratia por fundaciones, etc. ${ }^{81}$.

En la actualidad muchas amenazas a los derechos humanos no vienen siempre de los Estados, directamente, cuando de actores no estatales y de la incapacidad o de la falta de voluntad de los Estados de controlarlos. Esto ha llevado a que se plantee cada vez más la cuestión de la aplicación del Derecho internacional de los derechos humanos en la esfera privada y que se desee un cambio de concepción de la tradicional visión de los derechos humanos en la relación Estado-particulares. Esta aproximación tiene tanto dimensiones de derecho público como de derecho privado ${ }^{82}$

Se trataría de un cambio del enfoque estatocéntrico propio del Derecho internacional público a otro enfoque más propio de las necesidades actuales. Pero no es sencillo pues supone una ruptura de la tradicional distinción público/privado, estatal/no estatal, gubernamental/no gubernamental. La cuestión de las obligaciones de los actores no estatales se ha visto reforzada por fenómenos tales como la globalización de la economía internacional -y el poder de las multinacionales-, la privatización de servicios públicos (educación, salud, prisiones, agua, comunicaciones, fuerzas de seguridad), la fragmentación de

80 Vid. el comentario de Martin Burgos, J. A., «Inmunidades jurisdiccionales de los Estados, normas internacionales de la Unión Europea y Derechos humanos», Libro bomenaje a Dámaso Ruiz-Farabo Colomer, CGPJ, 2011, pp. 78 ss.; EsPosito Massici, C., Inmunidad del Estado y derechos humanos, Thomson, 2007; REQUEJO, M., «Transnacional human Rights claims against a State in the European area of freedom, justice and security - A view on ECJ judgement, 15 february 2007-C-292/65, Lechoritou and some recent regulations», The European Legal forum, 5-2007, pp. 206-211.

81 Vid. sobre esto Shelton, D., Remedies in International human Rights law, Oxford University Press, 2005-2006, 498 pp., p. 432.

82 Vid. Álvarez ToRne, M., «El derecho internacional privado ante las vulneraciones de derechos humanos cometidas por empresas y respuestas en la UE», REDI, vol. LXV (2013), 2, pp. 157191; BADGE, M., «Transboundary accountability for transnational corporations:using private civil claims», Chatam House, WP., 2006; MARÍN ORTEGA, O., Empresas multinacionales y derechos bumanos en Derecho internacional, Bosch, Barcelona, 2008; BONET PÉREZ, J., «Los actores privados de carácter económico y su incidencia en la formación y aplicación del Derecho internacional público: especial referencia a las empresas transnacionales», en Abellán, V., Bonet, J. (dirs.), La incidencia de la mundialización en la formación y aplicación del DIP, Bosch, Barcelona, 2008. 
los Estados y el poder de los grupos rebeldes no estatales, entre otros fenómenos $^{83}$.

El papel de las multinacionales en la sociedad internacional se vuelve a plantear en la descolonización, que consideraba que había injusticias estructurales que había que cambiar ${ }^{84}$. Algunos autores han centrado la denominada crisis del derecho internacional del desarrollo, que se produciría desde mediados-finales de los años noventa, en el contexto de la creciente presencia de las multinacionales en el escenario internacional, y en la penetración de una aproximación al desarrollo desde una ideología neoliberal ${ }^{85}$.

En esta línea las multinacionales y sus inversiones son las causantes en muchos casos de violaciones del Derecho internacional de los derechos humanos, en las situaciones más diversas. Por ejemplo el Delta del Níger, en Nigeria, es uno de los ecosistemas marinocosteros más relevantes de África debido a su biodiversidad y a la relevancia de las especies que alberga; además -como indica Adriana Espinosa ${ }^{86}$ - la riqueza de sus materias primas ha captado la atención de las potencias mundiales y corporaciones desde la época colonial. Shell, como ha analizado, Espinosa, empresa con sede en Holanda, tiene el $40 \%$ de la producción petrolífera de Nigeria, y es responsable de importantes daños medioambientales y de violaciones de derechos humanos vinculados a su labor. Así lo han constatado tribunales locales en Nigeria, en Holanda así como organismos regionales, como la Comisión africana de derechos humanos y de los pueblos y el Tribunal de Justicia de la CEDEAO, así como otros informes de órganos internacionales como el PNUMA. Su actividad en la región ha

83 Vid. un análisis en Clapham, A., Human Rights obligations of non-State actors, Oxford, 2006, 605 pp.Del mismo autor Human Rights in the private sphere, Clarendon Press, Oxofrd, 1993, 380 pp.

84 Vid. como ejemplo de esta aproximación Drai, R.; Thuan, C., Minh, T.; Bernard, J. P. y FonTAINE, J.M., Multinationales et droits de l'homme, Puf, 1984.

85 Lo que lleva, indica Teitelbaum, a un «desarrollo inhumano». Vid. su libro Teitelbaum, A., La crisis actual del derecho al desarrollo, Universidad de Deusto, Instituto de derechos humanos, Bilbao, 2000, 101 pp.

86 ESPINOSA, A., «La aplicación de la responsabilidad de respetar en situaciones de degradación ambiental: un apunte crítico a la luz del caso Shell en Nigeria», mimeo; vid. también de la misma autora «La justicia ambiental, hacia la igualdad en el disfrute del derecho a un medio ambiente sano», Universitas. Revista de filosofía, derecho y politica, $\mathrm{n}^{\circ} 16$ (2012), pp. 51-77; asimismo HerNÁNDEZ ZubiZarreta, J.; GONZÁleZ, E. y RAmiro, P., Diccionario crítico de empresas transnacionales. Claves para enfrentar el poder de las grandes corporaciones, Icaria, Barcelona, 2012. EBEKU, K., $\ll$ Constitutional right to a healthy environment and human rights approaches to environmental protection in Nigeria: Gbmre v. Shell revisited», RECIEL, vol. 16, $\mathrm{n}^{\circ}$ 3, pp. 312-320. Human rights Watch, The Price of oil. Corporate responsibility and human rights violations in Nigeria's oil producing communities, Nueva York, 1999. 
afectado a derechos tales como el derecho a la vida y a la integridad física, a la salud, al agua, a la alimentación, al trabajo y a un nivel de vida adecuado, etc.

Este es un botón de muestra de cómo las multinacionales, que no son sujetos de Derecho internacional a estos efectos, tienen comportamientos que afectan a los derechos humanos, siendo difícil que tanto desde la perspectiva del derecho internacional como del Derecho interno respondan por sus actos. La misma preocupación se extiende a otros ámbitos del comercio internacional y de las inversiones internacionales, principalmente. En algunos casos, como ha analizado A. Espinosa, se producen incluso violaciones de normas de ius cogens, en inversiones extranjeras, como sucedió en los asuntos Plama y Phoenix ${ }^{87}$.

Además, los Informes de relatores de Naciones Unidas indican que las industrias extractivas que realizan operaciones dentro de territorios indígenas o en proximidad de ellos están convirtiéndose en los más graves retos al ejercicio de los derechos de los pueblos indígenas. Esta situación se ve empeorada, como ha indicado el relator especial sobre la situación de los derechos humanos y las libertades fundamentales de los indígenas, James Anaya, por la falta de comprensión tanto de las normas básicas mínimas relativas a los efectos de las industrias extractivas sufridos por los pueblos indígenas como de la función y la responsabilidad del Estado para asegurar la protección de sus derechos ${ }^{88}$. En su análisis sobre la situación de los derechos de los pueblos indígenas en Perú, de 2014, pone de relieve el impacto de las industrias extractivas sobre los pueblos indígenas, que en décadas ha sido devastador, y que fundamentalmente se refiere a la contaminación medioambiental, la falta de participación, diálogo y consulta previa, en algunos casos. Asimismo analiza los casos de compensaciones y la participación en los beneficios. Por ello recomendaba una revisión del marco regulatorio y de programación del Estado sobre la protección de los derechos de los pueblos indígenas en el contexto de las industrias extractivas ${ }^{89}$.

87 Vid. el análisis de EsPiNOSA, A., «The assessment of corporate conduct towards human rights in investor-State disputes settlement: Why we should (and can mix) the sheep and the goats», Bussiness and buman rights, mimeo.

88 Vid. Informe del Relator especial sobre la situación de los derechos humanos y las libertades fundamentales de los indígenas, James Anaya, 11 de julio de 2011.

89 Vid. Informe del Relator especial sobre los derechos de los pueblos indígenas en Perú, en relación con las industrias extractivas, 7 de mayo de 2014; vid. asimismo las Observaciones sobre la situación de los pueblos indígenas en Guatemala en relación con los proyectos extractivos, y otro tipo de proyectos, en sus territorios tradicionales, de J. Anaya, de 7 de junio de 2011. 
No se trata de una preocupación nueva. Ya estaba en la aspiración de un Nuevo orden económico internacional ${ }^{90}$. Esto dará lugar a nuevos debates, como el de la conveniencia de otorgar a las multinacionales personalidad internacional. Autores como Charpentier se opusieron al considerar que tal posibilidad abriría las relaciones internacionales a grupos cuyo objetivo determinante es la rentabilidad, y que no están sometidos a ningún control político ${ }^{91}$. Este debate confundía las nociones de soberanía y personalidad jurídica. En nuestra opinión sería conveniente reconocer personalidad internacional a las multinacionales a los efectos de su control y responsabilidad. Hay que tener en cuenta que en los años sesenta o setenta la economía de mercado estaba dominada por los Estados, y las empresas no podían cambiar los engranajes del sistema económico internacional, pero en la actualidad esto ha cambiado, y se ha vuelto $<$ incontrolable $»^{92}$.

En la actualidad, al interpretar los principios rectores de Naciones Unidas sobre empresas y derechos humanos la doctrina suele poner la lupa en si aquellas cumplen sus obligaciones de debida diligencia en la materia ${ }^{93}$. Ibañez y Ordonez han examinado la debida diligencia, que conciben -al igual que $\mathrm{Na}$ ciones Unidas- como un proceso continuo de gestión para hacer frente a la responsabilidad de respetar los derechos humanos, en el que se debe incluir el concepto de riesgo (en tanto que impacto potencial que la actividad de la empresa puede tener para los derechos humanos). Para llevar a cabo la debida diligencia las empresas deben realizar un proceso de construcción permanente en todas las etapas de su actividad, desde la discusión de un proyecto a su desarrollo. Asimismo analizan el papel del Estado en la debida diligencia en derechos humanos, cuyo deber-cabe recordar- es el de proteger, respetar y

90 Vid. SpröTE, W., «Negociations on a United Code of conduct on transnacional Corporation», GYIL (1990), 331; MUCHILINSKI, P., «Attempts to extend the accountability of transnacional corporations: The role of UNCTAD», Kammirs, T., Zarifi, S. (eds)., Liability of Multinational corporations under International law, Kluwer, 2000, pp. 97-117; MARTIN-OrTEGA, O., Empresas multinacionales y derechos bumanos en el Derecho internacional, Bosch, Barcelona, 2008, p. 345; Alston, P., Non State actors and human Rights, Oxford University Press.

91 Charpentier, M.J., «Tendances de l'élaboration du droit international public coutumier», L'élaboration du droit international public, SFDI, París, 1975, p.pp. 105 ss, p. 129.

92 Bermejo García, R., «Las empresas transnacionales como actores y sujetos potenciales en la sociedad internacional», en Barranco, C., Celador, O., Vacas Fernández, F. (coords.), Perspectivas actuales de los sujetos de derecho, Colección Peces-Barba, $\mathrm{n}^{\circ}$ 2, Departamento de Derecho internacional, filosofía y eclesiástico, UC3M, 2012, pp. 89 ss.

93 Como ejemplo, el análisis de SIAC, C., «Due diligence in transnational mining projects: Mining registries and legal opinión issues», International and comparative mineral law and policy, Bastida, Walde y Warden-Fernández (eds.), Kluwer Law international, 2005, pp. 389-398. 
garantizar los derechos humanos. Se requiere de los Estados que el proceso de debida diligencia empresarial no quede en nada ${ }^{94}$.

Ahora bien, no hay que ocultar que como ha señalado la doctrina más especializada, la noción de debida diligencia, aplicada al propio Estado, en el ámbito de los derechos humanos, es decir su obligación de prevenir o investigar diligentemente las infracciones de los derechos y libertades reconocidos convencionalmente -en los órganos universales de protección- se concibe de manera «leve o blanda», «poco profunda en lo que al análisis de contenido de la noción se refiere y en ocasiones hasta incluso alejada de los postulados tradicionales $\gg^{95}$

De otro lado, se han impulsado de códigos de conducta para las empresas multinacionales $^{96}$-que han sido poco eficaces- o coaliciones en favor del cambio, como la que propuso Annan ${ }^{97}$ en 1999 para observar buenas prácticas. El 31 de enero de 1999 el SG ONU Kofi Annan impulsó en el Foro de Davos el Global compact que ha sido criticado por su carácter no vinculante, las lagunas de la iniciativa y por otras razones. El ECOSOC creó la Comisión de sociedades transnacionales. En 1998 se creó un grupo de trabajo para elaborar un nuevo código de conducta que, el 26 de agosto de 2003, presentó unas Normas de la ONU sobre la responsabilidad de las empresas transnacionales y otras empresas en relación con los derechos bumanos, que establecían obligaciones que debían seguir las empresas en materia de derechos humanos. Se trataba de un proyecto no vinculante. La Comisión de Derechos humanos adoptó el 20 de abril de 2005 una Resolución dirigida al Secretario General que cree la figura del Representante especial para los derechos humanos y las empresas transnacionales. Finalmente el 16 de julio de 2011 el Consejo de Derechos humanos aprobada unos principios para ordenar los efectos de las actuaciones de las transnacionales en materia de derechos humanos ${ }^{98}$. El Consejo hizo suyo el informe del Repre-

94 Vid. IbaÑEZ, P. y OrdoñEZ, V., «Papel de las empresas y de los Estados en la debida diligencia en derechos humanos», Revista colombiana de Derecho internacional (2014), 219-246.

95 En este sentido véase el estudio de Lozano Contreras, J.F., La noción de debida diligencia en Derecho internacional público, Universidad de Alicante, Atelier Libros, p. 264

96 Vid. MerciaI, P., Les entreprises multinationales en Droit international, Bruylant, Bruxelles, 1993, 414 pp. LADOR-LEDERER, J. J., International non governmental organizations and economic entities, Leyden, 1963; ANGEL, H.G., «Multinational corporate enterprises», RCADI, t. 125 (1968-III), pp. 447-600; SEIDL-HoHENVELDERN, Y., «International economic law», RCADI, 198 (1986-II), pp. 21-264; WALLACE, D., International regulation of multinational corporations, New York, 1976.

97 ANNAN, K., Un destino común. Un compromiso renovado. Memoria anual sobre la labor de la Organización, 2000, Nueva York, pár. 23, p. 7.

98 Vid. Márquez Carrasco, C., España y la implementación de los Principios Rectores de las Naciones Unidas sobre empresas y derechos humanos: oportunidades y desafios, VV.AA., Huygens, 2014, 791 
sentante especial del Secretario General sobre derechos humanos y empresas transnacionales impulsado por John Ruggie (A/HRC/17/31 de 21-III-2011). Estos principios rectores son en la actualidad una buena guía para la acción en pro de los derechos humanos tanto de los Estados como de las empresas, si bien plantean muchas cuestiones que exceden del objeto de esta contribución. Habría que vincular ambos proyectos, el del desarrollo sostenible y el de los principios rectores, pues la realización de unos y otros son interdependientes; habría, además, que intentar reconstruir una arquitectura institucional y normativa para estos retos. Estamos ahora en el inicio de un camino para domeñar la globalización. No es seguro que esta vía avance, pero es el único camino que sería coherente en la defensa de la humanidad, del interés público global, como se dice ahora.

En todo caso, además de vincular ambos proyectos se debería reforzar su juridicidad desde la perspectiva tanto del Derecho internacional como del Derecho interno. En esta línea, de un lado, el debate, ya analizado de la conversión de los principios rectores de 2011 en un tratado, que carece de consenso suficiente por el momento. De otro lado, algunos autores han planteado la necesidad de que las empresas multinacionales sean objeto de desarrollo mediante normas internas. En esta línea Simons y Macklin ${ }^{99}$ han analizado el caso de la empresa canadiense Talisman Energy INc's, empresa comprada por Repsol en 2015.

Antes, la empresa Talisman ha realizado actividades con serio impacto en Sudán, Perú, Australia, Indonesia, Malasia, Vietnam, Timor Oriental y Papúa Nueva Guinea, aunque también opera en Canadá (de donde era originaria) y Estados Unidos. En su libro estos autores consideran que hay ciertos vacíos de gobernanza que deberían ser remediados mediante el desarrollo por los Estados de reglas de Derecho interno. En el momento actual, y no solo porque el gobierno español esté en funciones, está parado el borrador Plan de Derechos humanos que había preparado el gobierno español. Estos autores consideran que deben desarrollarse normas que controlen a las multinacionales fuera de sus fronteras, cuando actúan en terceros países, en cuestiones que afectan a los derechos humanos.

pp. Esteve Molto, J., «Los principios rectores sobre las empresas transnacionales y los derechos humanos en el marco de las Naciones Unidas, para proteger, respetar y remediar: ¿Hacia la responsabilidad de las corporaciones o la complacencia institucional?», Anuario Español de Derecho internacional, vol. 27 (2011), pp. 317-35. HEINEMAN, A., «Business enterprises in public International law: the case for an International code of corporate responsibility», Essays in honour of Fudie B. Simma, Oxford University Press, 2011, pp. 718 ss.

99 SimOns, P. y MacKlin, A., The governance gap: Extractive Industries, buman rights and the home State Advantage, Routledge, London, 2014, 422 pp. 


\section{REFLEXIONES FINALES}

Los objetivos de desarrollo sostenible parecen plantear la necesidad de nuevas fronteras para el Derecho internacional, pues su realización afecta a la propia concepción del ordenamiento, tanto por lo que se refiere a la teoría de las fuentes como a la teoría de los sujetos; ambas parecen inadaptadas al reto planteado. El desarrollo sostenible constituye una noción compleja y multidimensional, que plantean desafíos en el plano económico, social y medioambiental y abre una nueva hoja de ruta para la Comunidad internacional, que puede servir de acicate para un desarrollo progresivo del derecho internacional.

Las características del reto (general, integral, universal, nuevo, revolucionario e indivisible) hacen que la naturaleza del derecho al desarrollo, tal y como había sido concebida, deba entenderse en otros términos. A nuestro juicio lo relevante del desarrollo sostenible ya no es el concebirlo o no como un derecho humano, sino el entenderlo como el derecho a un proceso, como un concepto puente y concepto síntesis que puede servir para la realización del desarrollo sostenible. En esa línea Rodrigo lo considera un marco metodológico. Estas aproximaciones, unas y otras nos alejan de los parámetros clásicos del ordenamiento internacional, como también lo hace el ser un derecho internacional por objetivos.

La dimensión finalista del derecho internacional no es nueva, ya la hemos visto en el Derecho internacional del desarrollo y en el derecho internacional de los derechos humanos. Pero lo que si es novedoso que esta visión finalista del derecho internacional, que aún mito y utopía como referentes de progreso del ordenamiento, tiene debilidades en cuanto a la exigibilidad. Tal vez esto se debe a que el valor de la solidaridad es uno de los que menos se han desarrollado, tanto en cuanto al principio de cooperación internacional (al desarrollo), que es un parámetro muy general de comportamiento, como a las obligaciones concretas. Además, en el marco de los desarrollos actuales y de la gobernanza de la sociedad internacional estamos con los ODS en el inicio de un nuevo camino, en un punto de partida -que no de llegada- cuyos instrumentos de desarrollo deberán desarrollarse para que, más allá de la retórica y los nuevos propósitos dotar de contenido y de juridicidad a los objetivos. La arquitectura normativa e institucional del desarrollo sostenible está por hacer, como también la posición jurídica de los actores y sujetos del orden internacional en la materia. 
